\title{
Prof. Sebastião Formosinho
}

\author{
ENTREVISTA CONDUZIDA POR M. J. MELO E F. PINA
}

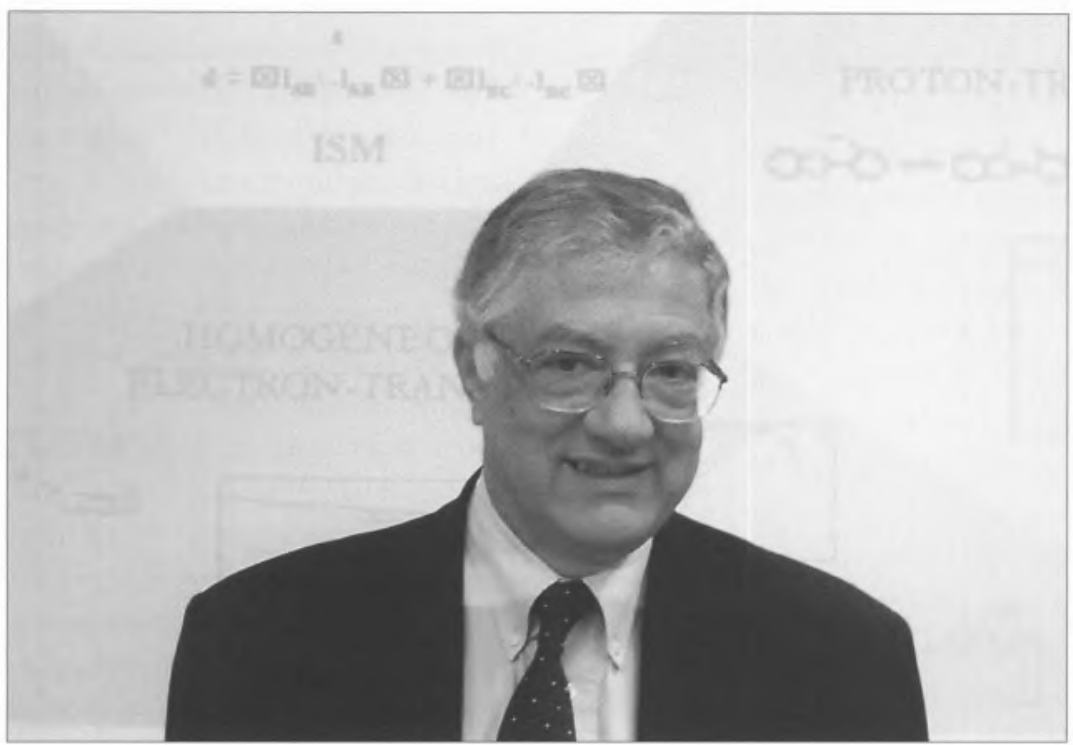

Quais foram as razões da sua escolha para o curso e para a carreira universitária. Foi a química a sua primeira opção?

Sim, já no sexto ano do liceu eu queria ir para química. Podia ser ou engenharia química ou físico-química; mas havia restrições económicas na família, os meus pais tinham-se deslocado para Coimbra exactamente para poderem dar educação aos filhos, e engenharia química nessa altura obrigava a três anos fora de Coimbra. Nessa conjuntura fui para físico-químicas. Mas a escoIha resultou não só da natureza da matéria, mas também de um professor que tive, o Dr. Fernando Morais Zamith professor do liceu D. João III, que foi o meu professor de físico-química durante todo o tempo de liceu, e que sem ser um grande mestre da palavra, preparava as suas lições, dava-as muito correctas e estimulava o estudo e o aprofundamento das matérias; foi daí. Quanto à parte chamava, eram seis, com os preparatórios em Coimbra de 3 anos, e com outros 3 ou em Lisboa ou no Porto.

Nasceu em Oeiras em 1943 mas estudou em Coimbra. Qual é de facto a cidade que sente como sua?

Bem eu diria que sou daquelas pessoas sem terra. É uma coisa que faz pena; o meu tempo de Oeiras era essencialmente o tempo de férias, onde depois da manhã de praia andávamos a pé, às vezes até Sintra, Queluz, caminhadas longas; esses lugares, onde eu os meus irmãos e os meus primos andávamos, desapareceram. Hoje não me reconheço de facto em Oeiras. Sou um homem educado nas Beiras, primeiro na Lousã, depois fui para Coimbra... portanto sou um sem terra. Os meus pais, no tempo da guerra, vieram para a Lousã; aliás o meu pai veio primeiro para o Fundão; o meu pai foi trabalhar na Companhia Eléctrica das Beiras. Uma família que eles conheciam de Oeiras, a família d' Orey, na altura era sócia da Companhia Eléctrica das Beiras, cuja sede era na Lousã; moveram-se para lá e ofereceram um emprego ao meu pai. Era o tempo da guerra e as dificuldades de emprego também determinavam a vida das pessoas.

Em 1966 está em Moçambique, como assistente. Uma viagem de Coimbra até Lourenço Marques (actual Maputo). Como foi esse percurso?

O Doutor Veiga Simão, professor de física em Coimbra, mas muito ligado à química, aliás chegou a reger química-física na química, era o Reitor e tinha a seu cargo montar a Universidade, na altura Estudos Gerais Universitários. Portanto 
havia um serviço que os diferentes departamentos prestaram, de deslocaçâo de pessoas para Moçambique; eu fui um dos destacados e lá fui.

\section{Não era voluntário?...}

Isto é ....essas coisas eram sempre entre uma medida de voluntariado e uma necessidade de serviço. Tinha ido o Doutor Redinha, depois foi o Vitor Crespo, esteve lá o Jorge Veiga também, havia uma rotação de pessoas, o Victor Lobo também esteve, o Rocha Gonçalves e o Cavaleiro; Coimbra esteve mais ligada a Lourenço Marques, e penso que Lisboa a Luanda.

E o seu serviço militar (1966-68) cumpriu-o em Moçambique...

Não, foi o primeiro ano em que, em Boane, houve curso de Oficiais Milicianos; mas como nós, eu e o Rocha Gonçalves, tínhamos sido mobilizados por Portugal, pela Metrópole, viemos. Aproveitei e vim de barco, foi agradável; fui para Mafra, como todos, e depois para o Entroncamento. Mas digamos a la longue o serviço militar é uma escola interessante, de condução de homens, pelo menos; eu cheguei a dar recrutas quando estive no Entroncamento, também fiz de Oficial de Justiça, coisas desse género.

Acabado o seu serviço militar, em 1968 vamos encontrá-lo em Londres a fazer doutoramento no laboratório do Prof. George Porter, Prémio Nobel da Química. De que modo marcou a sua vida o facto de ter estudado em Londres?

Bastante, na carreira de investigação. Para já porque o Prof. Porter tinha um grupo muito animado, era uma pessoa encantadora, disponível para os seus estudantes, uma vez que vivia na Royal Institution. Os temas eram interessantes, e no fundo só se fazia investigação. Tínhamos um compromisso de um dia por semana ir fazer de demonstrator no University College e fiz isso durante dois anos, mas depois no último ano já não fiz. Para além da investigação, tinha alguns aspectos culturais, a ciência de um certo clube Britânico. Era um ambiente agradável, onde aprendi bastante quer com o meu primeiro colega que hoje já está aposentado, o Colin Ashpole, quer com o Mike West, na fotofísica de compostos aromáticos em fase gasosa.

\section{Mas tinha um orientador ...}

O sistema funcionava da seguinte forma, havia uma pessoa mais avançada com quem eu fui metido a trabalhar, o Colin. Ele acabou o doutoramento e depois o Prof. Porter, dado que eu já dominava diversas questões da flash photolysis em fase gasosa, associou-me ac Mike West para fazer fotólise de relâmpago de LASER de nanosegundos em fase gasosa. Deu algum trabalho a montar aquilo, para deslocar o LASER, porque a fase gasosa estava ao lado no mesmo laboratório onde foi montada a fase liquida. Com o Michael Topp, tinha jâ nascido a fotólise de relâmpago de nanosegundos em fase líquida, e o Prof. Porter só deixava mover o LASER se mostrássemos que a experiência em fase gasosa teria sucesso. Portanto nós tivemos de mostrar os primeiros resultados sem mexer o LASER e assim fizemos a luz andar vários metros até conseguir entrar numa longa célula de 1 metro, colocada num forno. Depois, essa célula mais ninguém a conseguiu usar; o Graham Fleming que se seguiu nos estudos, partia sempre as linhas de vazio com aquela célula ...(risos...); acho que a colocaram no museu. Aquilo tinha alguma aprendizagem manual que veio do meu colega Colin Ashpole, para lidar com o momento de torção que criava na linha de vazio; fiz desde as clássicas chapas fotográficas para estudos de espectroscopia em fotólise de relâmpago, com sucessivos atrasos temporais da pequena lâmpada de flash, ainda feitas com as medidas de densitometria óptica para registrar os espectros e medir concentrações, até ao travelling microscope para medir os sinais do osciloscópio, à antiga. Depois, evoluiu tudo, .... nessa altura não havia dinheiro para comprar uma lâmpada de Xenon, teve de ser uma de iodo-quartzo metida num bolbo prateado, para aumentar a intensidade da luz; mas com esses aspectos interessantes, digamos laboratoriais, aprendeu-se muito e saíram resultados muito interessantes. Deu-me um bom back- ground de experiência laboratorial e de teoria cinética.

Pode dizer-se que, de certa maneira, o trabalho que veio a desenvolver no futuro dependeu muito deste seu doutoramento?

Durante um tempo segui na mesma linha de estudo de rendimentos de tripletos de compostos aromáticos, em função da pressāo. Depois o problema ficou muito controverso, tivemos muita dificuldade em publicar; acabei por o resolver de uma forma ou de outra, publicando numa revista portuguesa, que é sempre uma solução de recurso perante várias resistências. Depois ao longo do percurso, e após dois ou três anos cá em Portugal, surgiu uma teoria, a teoria do efeito de túnel, que foi aplicada às transições não radiativas e depois às reacções fotoquímicas; tema este também controverso, mas que se veio a desenvolver de forma aceitável. Nessa altura uma revista, Molecular Photochemistry, foi muito aberta a receber esse tipo de artigos, ao ponto de um colega meu inglês, um dia me dizer, a propósito de um artigo sobre transições não radiativas em exciplexos e excímeros, que era o melhor que tinha sido publicado no ano. Ao que respondi - de certeza que não porque foi rejeitado na Faraday'. Também não estou convencido que tivesse sido o melhor publicado em fotoquímica nesse ano, mas revela as dificuldades que havia. 0 Molecular Photochemistry aceitou tais trabalhos e durante muito tempo assim fui lá publicando, mesmo atẻ um outro artigo mais controverso ligado ao efeito da pressão no rendimento de formação do tripleto do antraceno. Porque o grande problema do efeito da pressão era entenderem que a densidade de estados do estado $T_{1}$, deveria ser tão forte que o cruzamento intersistemas não podia ser reversível, não podia voltar para trás. Essa não era a nossa ideia porque viamos, em conjunto, o singuleto e o tripleto excitados, mas isso foi um problema controverso que julgo não ficou inteiramente esclarecido, nem por nós nem por outros investigadores. Penso que quem o poderia ter feito não estava metido no campo. 
Desde 1979 que é Professor Catedrático em Coimbra. Em muitos sectores da sociedade portuguesa há um preconceito que a Universidade de Coimbra é muito conservadora. Concorda?

Bem ... a Universidade é de facto um pouco conservadora. De qualquer maneira o Departamento de Química sempre seguiu por tradição uma política de qualidade, isto é de escolher em função da qualidade e nâo tanto da antiguidade. Isso reflectiu-se no facto de eu ir a catedrático muito cedo. Esta era uma política que já vinha do passado. Sem entrar em grandes histórias, certos professores, porque na altura os júris eram muito grandes, por exemplo os da especialidade apostariam num candidato, mas a química tinha muita influência na faculdade e no fundo o candidato que a química apoiava era o escolhido. Isto aconteceu por diversas vezes, nâo foi caso único na Faculdade de Ciências.

Em que época a química tinha essa capacidade de influenciar?

Bem, estamos nos anos sessenta, setenta. A química moldou a faculdade, porque começou muito cedo a sua ligação ao estrangeiro, com a preparação de doutoramentos. Aliás fê-lo simultaneamente com a física, o Prof. Jorge Andrade Gouveia, que faleceu recentemente, pela química, e o Prof. Mário Silva pela física. Mas o Prof. Mário Silva depois teve os problemas políticos que levaram à sua demissão e portanto a física ficou amputada dessa linha de pensamento e foi a própria química como departamento que foi ajudando a física a percorrer esse mesmo percurso. Claro que muitas pessoas da química foram para o estrangeiro, na altura praticamente nāo havia doutoramentos no País. A química marcava o ritmo da faculdade, e dava alguma colaboração a outros departamentos que quisessem seguir esse mesmo ritmo como foi o caso da física. Tinha influência na Faculdade.

Mudando um pouco de tema, regressando ao presente, segundo um estudo da Comunidade Europeia, os Portugueses são, de toda a comunidade, os menos informados sobre Ciência e Tec- nologia e consequentemente são os que se interessam menos pela leitura desses temas. Tem alguma hipótese explicativa para este facto e sobre como é que nós poderíamos inverter esta situação?

Queria abordar este assunto sobre dois pontos de vista; um é um artigo interessante do João Caraça, publicado na revistas Artes, Letras e Ideias ${ }^{2}$ onde ele diz que no governo anterior, a expressão do Ministério da Ciência e Tecnologia era uma tentativa para que a ciência começasse a influenciar muitos sectores da actividade da sociedade e do estado, que não apenas as universidades. Verificou-se que assim não foi, inclusivé na própria indústria. Há uma incapacidade ou dificuldade da sociedade portuguesa em aderir à ciência, reconhecer a importância da ciência como factor motriz da sociedade, para além, enfim, de dificuldades políticas. A ciência cria algumas restrições aos políticos, não é?...aliás Karl Popper dizia que o grande problema não era ter maus políticos, era tentar ver como é que a democracia podia, com políticos correntes, evitar que eles cometessem erros muito graves para a sociedade. A ciência é um desses meios. Mas claro que limita também o poder dos políticos. Por exemplo, na questão da co-incineração...

\section{já voltamos lá...}

...Mostra como é que o poder político entende a ciência. Recorre à ciência, a respeito da taxa de alcoolémia, porque Ihe convém; nessa altura pergunta o que é que se passa na Europa, o que é que os cientistas dizem; mas quando não Ihe convém ignora. A atitude da sociedade, do País, perante a Ciência não pode ser esta. Eu julgo que Portugal perdeu a revolução industrial, isso teria sido um factor para a ciência aumentar a sua influência. 0 doutor Salazar era, mais do que ser autoritário, essencialmente um homem de equilíbrios. A Igreja, as Forças Armadas, as Universidades, as Corporações, valores que ele equilibrava e que transformou em valores da sociedade; para ele, a indústria era apenas o mínimo necessário para poder resolver alguns problemas de alimentação, muito graves, na sociedade portuguesa, mas nunca entendeu a indústria como o motor da sociedade. Claro que depois, a alguns ministros ele lá foi permitindo alguma estratégia, e a indústria acabou por dar a volta à sociedade, mas muito tardiamente, muito lentamente. Há factores históricos que, julgo eu, condicionam a sociedade portuguesa.

e neste momento o desinteresse do cidadão comum tem a ver também com uma vontade política...

.em parte, em parte...

quando nós podíamos tentar inverter ...

essas oportunidades foram pouco aproveitadas; até em temas do interesse imediato do cidadão, em que a ciência é importante, por exemplo na alimentação; se a mensagem fosse correcta haveria outras oportunidades, mas as mensagens, feitas por pessoas com responsabilidade, normalmente são muito ruidosas, muito controversas; e assim, o cidadão comum, coitado, fica perfeitamente perdido,

O Prof. Formosinho sendo uma pessoa muito cordata e tranquila, tem no entanto sido protagonista de algumas polémicas. Nesta entrevista gostaríamos de abordar duas delas. A do modelo de intersecção de estados ${ }^{3}$ e a da co-incineração. No que respeita à primeira, e tendo em conta o título de duas das suas obras ${ }^{4}$, considera-se um heterodoxo científico?

Infelizmente julgo que sim, não por minha vontade; um dia a secretária do Prof. Porter, a Judith, disse-me "Sebastian you like to be controversial" e eu respondi-Ihe que não, e de facto não gosto.

ah!, mas já remonta a esse tempo...

..risos...já remonta a esses tempos. 0 trabalho de doutoramento tinha uma linha que foi controversa, aliás criada pelo próprio Prof. Porter, só que o Prof. Porter moveu-se rapidamente da controvérsia...risos...e eu mantive-me na controvérsia. Depois a teoria do efeito de túnel teve alguma controvérsia e o modelo de intersecção de estados atinge o 
auge. No entanto, no que diz respeito a relações pessoais, nós e os colegas com que lidamos somos impecáveis. Por exemplo, mesmo com o Prof. Marcus ${ }^{5}$, onde potencialmente os conflitos mais se poderiam acentuar. Houve um congresso no Algarve, o Prof. Marcus no dia seguinte ao da minha conferência disse-me, "Sebastian, I should have said you were very good". Jantámos juntos com as respectivas esposas, pediu-me boleia para Lisboa, viemos a conversar sobre tudo, menos ciência. Mandou-me um excelente cartão de Natal, onde felicita a minha mulher pelo trabalho, que era em química, e a mim por outra coisa qualquer, que não podia ser o trabalho. Quando vejo que começa a ser uma situação incómoda, mudo de tema. Não pressiono as pessoas para isso. Houve uma vez uma conferência em Amesterdão, que fui a convite do Jan Verhooven, onde um colega dele ficou muito perturbado com o que eu disse; perguntou-me "qual era a experiência crucial que faria para provar o seu modelo contra o de Marcus", respondi "uma experiência em fase gasosa, se o solvente tem importância e se o Marcus tem razão, a barreira há-de ser maior em líquidos do que em fase gasosa", e ainda acrescentei que "já foi feita uma experiência assim, pelo Nelsen". Ao descrever o resultado em que as barreiras eram comparáveis e não eram superiores em solução, ele ainda argumentou "que a reorganização interna era importante", mas eu repliquei "que teria sempre o solvente, e dei o valor da barreira do solvente". Ai os estudantes começaram-se a rir, ele ficou furioso e desapareceu. Mas tinha de ir jantar comigo. No jantar eu não tratei nada disso, ainda me acompanhou a conversar até próximo da hotel; tenho alguma diplomacia, porque já basta esta inevitabilidade. Agora é um problema sociológico complicado que tenho tentado perceber; mas ter a capacidade de o mudar não é fácil. Temos sido muito insistentes, o modelo de intersecção de estados já vem de há dezassete anos.

Uma das observações que se fazem ao seu modelo de intersecção de estados, é a de que não é de fácil utilização e também de visualização. Quer comentar?

Sim, desse ponto de vista é um aspecto importante e estamos a trabalhar no sentido de ter "software" de "friendly environment", algo que seja fácil de utilizar. Quanto aos conceitos eu julgo que eles são claros, mas sendo claros para nós, talvez não o sejam para outras pessoas. Evidentemente que é muito mais complicado que a teoria de Marcus, indiscutivelmente. E portanto há um trabalho aí a fazer-se, mas como ainda não conseguimos resolver alguns problemas a montante, como as publicações de artigos, não temos tempo e motivação para o resto; por exemplo, no que diz respeito à transferência de electrões, já se aproxima do equilíbrio suficiente, após ter saido um extenso artigo de revisão no Prog. Reaction Kinetics; no entanto, quanto à utilização do modelo para a reacção de transferência de átomos, cálculo absoluto de constantes cinéticas em função da temperatura, efeitos isotópicos cinéticos, aí já estamos há quatro anos para conseguir publicar. Temos estado envolvidos em problemas muito de base para conseguirmos tratar então dos aspectos de divulgação. E depois para que as coisas avancem é sempre preciso uma pequena comunidade que o entenda e utilize; nesse sentido, pelo menos já temos um bom artigo do Patrice Jacques, que utiliza o modelo ${ }^{6}$. Ele teve imensas dificuldades em publicar. Teve de sublicar numa revista Suiça, num artgo em homenagem ao Prof. André Braun. Não conseguiu publicar nos Estados Unidos como é óbvio. Também isso afasta as pessoas. Neste caso, eles entenderam muito bem os conceitos; o colaborador dele que é luso-francês, Manuel Dossot, tirou algumas dúvidas com o Luis Arnaut, mas por eles mesmos chegaram aos conceitos. Tiveram alguma motivação porque tinham dificuldades em resolver um problema. Agora digamos, meteram-se num caminho terrivel...risos...

Foi presidente da recentemente extinta, comissão científica independente (CCI) nomeada pelo Parlamento com o objectivo de estudar a co-incineração. Concorda com a conclusão de que a
Ciência saiu derrotada pelos políticos, pelo menos por alguns políticos?

Eu julgo que não, sobre esse ponto de vista não, porque o resultado permanece. Aliás o resultado não tem nada de novo, o resultado é apenas uma explanação a nível mais detalhado do consenso que se tem estabelecido ao longo destes anos, nos grupos que trabalham em problemas ambientais e tratamento de resíduos, que já passou às formas legais; portanto, o consenso é vasto. Não houve grande inovação. Mas o resultado perante a comunidade portuguesa mantém-se. A nossa página da internet tem tido sempre muitas consultas. Portanto há algum tipo de leitores que estão interessados em ser esclarecidos. Agora como dizia o doutor Salazar "em política tudo o que parece é", logo é evidente que a comissão foi derrotada neste presente momento por uma opçâo política de "não à co-incineração". Evidentemente que não teria problema nenhum, se houvesse alternativas crediveis e fáceis. O Governo e o Parlamento têm competência para legislar nessa matéria e não deviam nunca ter abdicado dos poderes que the competem. Claro que teria sido preferivel ter sido pedido um parecer antes; mas foi o parlamento que criou essa comissão e the garantiu os poderes, com votos maioritários do PS, com certeza do próprio PSD, do PP e até acho que do PCP. Porque ninguém quer ser dado como obscurantista. A Ciência, sim senhor, é um árbitro excelente, até que haja uns resultados, porque depois cada um teve as suas ideias, como se viu. Portanto, acho que é um problema também de ética. Se o parlamento, mal ou bem, usou aquelas regras e ele próprio decidiu criar uma comissẫo, porque se alterou a maioria não deve esquecer as regras a que se tinha comprometido. Já na altura houve um "grande engasganço" quando a comissão produziu o primeiro relatório; tanto que pediram um segundo relatório, com um grupo médico. Mas a partir daí já não tiveram cara para mais e portanto deixaram prosseguir as recomendaçōes da comissão. O problema estaria resolvido para bem do País; porque se mostrou nos testes que se fizeram, que a co-incineração destrói os resíduos, aproveita a 
energia dos resíduos, tudo sem criar impactos adicionais à cimenteira a funcionar normalmente. É tudo um efeito psicológico. Claro, dir-se-á que as pessoas funcionam com o senso comum, os habitantes não querem os residuos lá; começam a ver os resíduos cada vez mais perigosos à medida que se aproximam de Souselas ou de Coimbra. No fundo eles são é perigosos quando são abandonados nos cursos de água e noutros lados. Houve muita perturbação, porque diversas pessoas fomentarem e alimentarem essa ideia; dizia-se que os bebés iam morrer ou nascer com defeitos, apresentaram-se nos jornais factores cinquenta vezes maiores que as emissões de dioxinas que a lei permite, e quinhentas vezes superiores às realmente medidas. Houve um esquema complicado de perturbar a opinião pública, e evidentemente havia muitos interesses em jogo. Agora qual é a solução? O PSD poderia ter retomado a incineração dedicada; no passado, chegou a estar indigitado um director que era um professor do ambiente de Aveiro, mas o consórcio comercial como houve uma alteração de classificação do tipo de resíduos classificados como perigosos, fez as contas e achou que aquilo já não era viável. E por isso é que o governo, já do partido socialista, pensou que a co-incineração podia ser uma solução. Mas este governo tem uma dificuldade, porque ainda que tenha aumentado o número de resíduos porque a classificação foi alterada outra vez, os problemas que se colocam a pôr os resíduos numa cimenteira, são os mesmos que se colocam numa incineração dedicada. Ainda por cima agora agravados com um parecer que diz ser preferivel a co-incineração. Não há incineradoras dedicadas para resíduos industriais perigosos construídas na Europa desde 1995. Provou-se que a outra alternativa, a co-incineração, é melhor e mais barata. 0 resto são soluções esotéricas. $\mathrm{O}$ governo meteu-se num beco sem saída.

A sua resposta leva-nos a perguntar se vale a pena polemizar ciência nos jornais, perante um público geralmente pouco informado, em que argumentos por vezes pueris, ou mesmo demagógi- cos, acabam por fazer opinião com tanta eficiência ou mais, que os verdadeiros argumentos científicos baseados no estudo e na experimentação?

Julgo que o grande critério é o estudo e a experimentação. $E$ essa mensagem tem de se transmitir ao público. A comissão tratou de dois aspectos que pareceram correctos do ponto de vista do público, para os habitantes das regiōes que não querem o lixo no seu quintal. Tentou-se usar argumentos de analogias de senso comum. Por exemplo, os metais pesados. Nós colocamos restrições de modo a que o cimento passa a ter em metais pesados o mesmo teor que uma rocha natural. Como as pessoas não têm medo das rochas naturais não houve grande polémica, não teve grande ressonância. Nas dioxinas tentámos fazer a analogia com a queima de madeira nas lareiras. Na altura não havia medidas directas, típicas e representativas, porque depende do tipo de madeira, se são madeiras contaminadas ou não, etc. Infelizmente, só muito recentemente, apareceram dados sobre a queima dos residuos do fundo do quintal em bidão, que é muito pior que as lareiras, mas já toda a controvérsia estava lançada. Foram medidas directas de lixo americano. Na altura, alguém da Quercus disse "ah!, mas não é representativo porque o lixo americano é diferente do português". No entanto, o ex-presidente da Quercus, o Francisco Ferreira, utilizou esses dados para estimar quanto é que viria do encerramento das lixeiras, admitindo que aquilo estava a arder completamente. Isto não quer dizer que a Quercus represente uma autoridade no assunto, antes pelo contrário, mas por coerência ele também usou esses dados. A ideia era passar algo do senso comum, que as pessoas entendessem. Mas claro, se isso que é do senso comum ainda é mais controverso que a própria solução...tudo só se complicou. Dissemos, "Isto é equivalente a 170 lareiras", até podiam ser 300 , tudo bem. Mas logo uns a dizer isto são 170 mil ...risos... aquilo não durou muito tempo, mas ficou essa imagem.
Qual o papel em todo este processo dos chamados sociólogos "pós-modernos" ?

Nós hoje estamos mergulhados num ambiente conduzido por sociólogos que advogam que a ciência é uma construção cultural, sem nada a ver com a realidade. O valor da ciência é igual ao do "Vodu", colocam tudo no mesmo plano. Baseiam-se em estudo de casos; para eles, a sua experimentação tem um valor absoluto, só na ciência é que não tem. Ora nós sabemos que a ciência tem os seus sucessos, não é só, por exemplo, o desvio dos raios luminosos previsto pela teoria da relatividade durante um eclipse, ou a ida do homem à Lua, ou os medicamentos. Agora a visão que se passa para a sociedade, que a ciência é uma actividade social sem qualquer ligação à experimentação e à realidade, dissolve alguma confiança que o público tem na ciência. Isso foi muito jogado a propósito da co-incineração, porque o debate se pautava nestes termos; a opinião que vinha num jornal é tão válida como a opinião da comissão, que tinha um consenso internacional por trás.

No jornal Público, nas pequenas notas que todos os dias saem na última página, passou-se a mensagem que a CCI nunca poderia contrariar a co-incineração porque perderia o emprego. Sendo o Prof. Formosinho, uma figura respeitada pela comunidade científica, por tantos motivos entre os quais a sua honestidade e dedicação à Ciência, como se sente perante estas provocações. Está arrependido de ter aceite esta tarefa?

Julgo que não, aliás todos os que fomos indicados aceitámos. Portanto é um problema, digamos, talvez de alguma inocência, mas entendemos que é um serviço que se deve prestar; por vezes os cientistas acusam o Governo de não solicitar o apoio à ciência, agora, se a primeira vez que sẫo chamados, recusam, é-se incoerente. Preparámo-nos para o debate. Chegámos a fazer uma queixa contra o jornal "O Público" na Alta Autoridade para a Comunicação e pelo menos algo ficou provado; "o Públi$\mathrm{CO}^{\circ}$ teve uma advertência pela falta de 
objectividade e rigor em diversas questões técnicas. É evidente que coisas como a que fez referência são mínimas no contexto do problema e não nos incomodam em demasia. Mas foi um dos argumentos que nós mesmos colocámos logo de início, quando nos reunimos. Temos este dilema: se nós decidirmos pela co-incineração por ser a melhor solução, começam-nos a acusar de que queremos "o tacho"; mas se para evitar isso apontarmos outra solução pior, não é bom nem é lógico. Nós temos de ser independentes dessa conjuntura. Claro que foi mau que o Parlamento tivesse criado essa conjuntura, mas também não há grande solução. Julgo que em Inglaterra há algumas comissões que as pessoas depois recebem, não um vencimento fixo, mas por esquemas um pouco diferentes. Assim com a $\mathrm{CCl}$, pelo menos a situação é transparente. Eu julgo, e posso não estar correcto, que para conferir à comissão, como o Parlamento colocou, uma autoridade de uma administração ou uma entidade administrativa independente, quiseram dar-lhe a categoria de uma Direcção-Geral. E portanto tudo decorre dessa situação. Mas isso é algo que não nos preocupa muito, faz parte deste bruuah!, de entrada numa situação de grande confronto, quer na televisão, quer nos jornais, quer nos debates: e também de uma certa mise-en-céne que estas coisas têm de ter.

Tem desempenhado vários cargos de relevância para a Sociedade, quer presidindo a comissões e organizações científicas, quer como Secretário de Estado. Pensa que conseguiu contribuir para uma maior sensibilização do poder político no que diz respeito à importância da Ciência na Sociedade Democrática?

Isto é, na altura em que fui Secretário de Estado, 1980-81, julgo que o governo que o Dr. Sá-Carneiro tinha constituído era um bom Governo. E havia alguma sensibilidade aos problemas da Ciência. Era uma caminhada que também veio com a JNICT, o INIC; a JNICT mais aberta à sociedade, o INIC mais vocacionado para apoiar a Universidade. A sensibilidade foi mais em termos econó- micos, financeiros, mas talvez ainda, por esta época, em 1980 em Portugal, a ciência ainda não tivesse o papel que hoje tem na nova economia. Apesar de tudo, nessa altura foi criada uma espécie de conselho de ministros restrito; como há para as finanças, para a ciência havia um mini-conselho, com o ministro da Educação, com o Ministro da Agricultura e com outro conjunto de Ministros, onde a Ciência podia ter algum reflexo. Se isso tivesse prosseguido, esse tipo de acçầo política, eu julgo que esses aspectos poderiam ter tido mais sustentabilidade. Mesmo assim, na altura a carreira de investigação foi também muito difícil de ser publicada. Era uma tentativa de que instituições que não fosse só o Ministério da Educação tivessem investigadores para prosseguir as tarefas de investigação importantes fora do $M E$, na agricultura nomeadamente, na Indústria; diploma que aliás um outro ministro, o Mariano Gago, depois reformulou ligeiramente e tentou manter essa política. Era uma política que teria alguns reflexos, mas que esteve muito dependente de outros factores; julgo que hoje se vê que a ciência e a investigaçâo é sempre tomada como acessória. Aliás uma das dificuldades que se levantavam à época, era dita pelo Ministério das Finanças em termos claros: no fundo a investigação está feita por professores universitários, não é preciso mais. Mais ou menos essa era a ideia. Não! A investigação, e hoje cada vez mais, interessa a diversos sectores da sociedade; é muito importante para criar novo saber e novas tecnologias, e portanto era um caminho que provinha de uma dinamização do Ministério da Educaçẫo e das Universidades. Tal como aconteceu agora outra vez, com o sentido do Ministério da Ciência, esta perspectiva colapsou um pouco.

Considera-se um cientista ou um político, ou um político cientista?

Eu considero-me um cientista se bem que, o meu chefe de gabinete me disse que um Reitor que depois enveredou inteiramente pela carreira política dizia "0 Formosinho Sanches não gosta de fazer política, mas sabe fazer politica". Talvez isso corresponda à verdade. Eu não gosto de fazer política, mas às vezes é necessário fazer política. Não só governativa, como quando estive no poder, mesmo na questão da co-incineração foi necessário fazer política, na universidade é necessário fazer política. Alguns problemas dão-nos prazer resolver, mas nem todos; a maior parte é uma estopada que tem de se fazer. 0 que também noto é que sou mais eficiente quando estou mais afastado das relaçōes pessoais. 0 poder para ser bem exercido carece de um certo distanciamento. Isso é outra das dificuldades que a Universidade Portuguesa tem, um excesso de "inbreeding" que dificulta muito a evolução das relações de poder na própria Universidade. Foi-se de um extremo para o outro, antigamente o poder estava só nos catedráticos. Hoje está mais diluído. E também há muitos catedráticos, no passado havia poucos; quando fui a catedrático havia quatro...no meu departamento.

\section{Há quem diga que o que deveria haver} era muitos mais? ${ }^{7}$.

...mas isso é um problema de promoção. Se calhar no sistema americano pode haver muitos catedráticos, mas a partilha de poder entre eles é diferente da daqui. Os Ingleses talvez tenham o sistema antigo. Uma vez estava em York e perguntaram-me "o vosso Departamento é daqueles que tem muitos Catedráticos ou poucos?" Era a grande distinção que eles colocavam. Porque aí o Catedrático, o Professor inglês tem o poder. O Professor americano é promovido pela qualidade, por trazer dinheiro, etc., mas se calhar depois têm sistemas muito complicados para nomear o Director, que nāo são só os Universitários, há intervenções do Board of Trustees, da sociedade, etc.; esse têm depois quase todo o poder, até para extinguir departamentos e coisas assim. É um problema de relaçōes de poder. No modo como nós exercemos o poder, se os Catedráticos detêm poder, então haverá poucos; se a promoção é por qualidade, poderá haver muitos, mas então o modo de organização do poder tem de ser talvez com um director; por exemplo, uma nomeação nẫo só por intervenção dos pares, mas também de gru- 
pos da sociedade, da indústria, não sei se da autarquia.

Mas isso seria um modelo viável aqui em Portugal?

Desconfio... risos., nós temos uma tradição longa que nāo se muda rapidamente.

O Prof. Formosinho tem tido um papel muito activo na Universidade Católica. Como vê a utilidade actual e futura das Universidades privadas?

Do que eu fiquei consciente, quando assumi funções mais elevadas a nivel das Beiras na Universidade Católica, foi que o número de alunos iria diminuir acentuadamente, o que haveria de criar um problema financeiro complicado e a Universidade teria de mudar. Nesses sete, oito, nove anos, começámos a desenhar áreas mais apelativas para os estudantes, a enveredar por prestações de serviços mais relevantes para a sociedade, e a entrar numa era de patentes. E usar as patentes nâo como um mero valor de conhecimento que se troca de imediato por dinheiro, mas como uma área de negócios. Por exemplo há agora uma patente que a Universidade tem, denominada HEINET (human education interactive network), ligada à intervenção em tempo real de diversos parceiros, um tipo de conferência de imprensa, que pode ser feita com a internet e intranet, pode ser feita com os estudantes entre si, com o professor, etc; é uma patente que vai ser comercializada, pelo menos para a parte de medicina dentária, com uma firma Finlandesa. Há ainda outras patentes mas esta é a que está mais avançada. Neste tipo de actuação, uma Universidade do Estado tem dois problemas. Um são as dificuldades próprias dos orçamentos do Estado; a outra é que nelas o poder está muito diluído para definir estratégias consistentes e sustentáveis.

\section{Com a excepção da Universidade de} Aveiro...

..sim que tem uma estratégia mais bem conseguida, até porque mesmo no que diz respeito às verbas de investigação, elas são canalizadas para estratégias da Universidade, talvez definidas pelo Rei- tor, ou pela Reitoria, ou pelo núcleo duro da Universidade..

Essa é a minha visão. É interessante e muito aliciante ver uma Universidade evoluir nesse sentido. Mas dir-se-á que a Universidade terá sempre necessidade de ter estudantes. Com certeza que sim, alguns; mas passa a ser um conhecimento transmitido com um valor económico.

\section{Vê uma Universidade privada como} algo complementar de uma Universidade pública?

..sim... e pode criar modelos, protótipos, particularmente em Viseu, onde o tamanho é muito mais pequeno, podem surgir modelos de incentivo para as outras Universidades. A Católica aliás, já o tinha feito no passado, por exemplo com o curso de gestão; na altura, praticamente não havia gestão em Portugal, mas foi aí que tudo se iniciou, depois outras copiaram, talvez em excesso. A Biotecnologia também começou na Católica, há muitos anos, depois teve outras duplicaçōes; Engenharia Industrial, foi um curso iniciado na Figueira, os alunos têm tido boa colocação no mercado. Também essa função de modelos a testar, pode ser útil para as Universidades do Estado.

Na Universidade discute-se bastante o problema do decréscimo de vocações para as áreas científicas e tecnológicas. De que forma poderemos evitar este problema? Será que pode prejudicar a Universidade e a própria sociedade?

Julgo que sim, mas resulta também muito da estrutura da sociedade. No tempo em que eu era estudante, ir para medicina não era estimulante. Aliás a minha mãe queria que eu fosse para medicina, e eu que via o meu tio, que tinha que se levantar a "deshoras", disse logo que não. Eu gosto de dormir as minhas horas e não fui cativado por uma vocação de cuidar das pessoas, de ser útil assim. Hoje não é por essa razão por que escolhem o curso de Medicina; essa vocação existe em alguns, mas é por um problema económico na sociedade que Medicina é tão procurada. A sociedade está organizada de tal manei- ra que a Ciência não tem uma expressão económica condizente. Os engenheiros, excepto quando evoluem na carreira e passam a ganhar bem, no inicio têm níveis salariais moderados, comparados se calhar com algum gestor. Depois as ciências são muito mais duras de aprender, requerem a Matemática, a Física, a Química, eh! c'os diabos, a gestão faz-se mais facilmente, ou a sociologia ...

Mas isso poderia funcionar como uma barreira positiva, porque a selecção faz-se pela vocação...

Mas no fundo como se faz só pelas notas, e as notas têm muitos ruídos complicados porque não há nada standartizado, não funciona. Agora como fomentar socialmente a Ciência? Aos professores resta-nos a beleza intrínseca das matérias e da sua importância social. Mas como o problema é universal, revela-se que a mensagem não está a passar, e em sociedades como a alemā, onde a indústria Química foi um portentado, alguém me dizia, pela primeira vez um dos administradores da Bayer não é químico. Um reflexo da degradação a que se tinha chegado nesse dominio. Portanto há problemas de componentes sociais muito fortes que estão a perturbar a vocação, e julgo também que a dificuldade das matérias.

\section{E acha que podemos inverter...}

Eu julgo que sim, isto é, existem até algumas soluções radicais; não sei se se deveria ser tão radical. Mas vejamos, um estudante de medicina entra no curso, e antes de começar o contacto com o doente e a ir para aquilo que o motivou, passa três anos a estudar ciências básicas, etc.; actualmente há organizações onde o estudante começa desde muito cedo a entrar no hospital, a ver casos, a circular com os médicos, por exemplo ir uma vez por semana a uma clínica dentária, para o motivar. Depois todos os conteúdos têm de ser reprogramados de modo a não se estudar só em abstracto. Pode-se estudar um osso por exemplo ligado a uma veia, que passa aqui...ou tratar de um dente e um nervo, tudo já num contexto mais global do doente. Na Química os estu- 
dantes começam a render quando entram na parte do estágio, que permite uma visão global, e nós espantamo-nos...foram tão maus estudantes até ali, como é que começam a funcionar bem? Talvez que o ensino tenha de se mudar radicalmente.

Mas isso era o modelo antigo, quando havia poucos alunos, que ao ingressar na Universidade começavam logo fazer investigação com um professor. Como é que com turmas de 60 alunos...

Vamos ter menos alunos, claramente.

Podemos aproveitar para fazer a tal revisão da qualidade?

Sim. Sim.

E acha que a comunidade científica vai ter força para impor, uma opção desse género? $\mathrm{O}$ aluno vai sair mais caro.

Claro, esse é o problema económico, dos custos actuais. Portugal até das estatísticas se revela que tem investido financeiramente muito em educação. Os resultados têm sido bastante maus, por exemplo a nível do ensino básico e secundário. No universitário ainda não há esses estudos de comparação. Não sei... é um problema económico. Desde que os niveis de financiamento das Universidades se mantenham e não forem feitos por aluno.

\section{Mas estão a ser feitos por aluno...}

Estão, o problema é saber quando houver um decréscimo de alunos se o Estado estará predisposto a manter o nível de financiamento, apesar de haver menos alunos, e se a Universidade está disposta a reformular profundamente 0 seu método de ensino.

Esta pode ser uma boa altura...

É uma oportunidade que a Universidade poderá agarrar, mas é evidente nós temos globalmente um excesso de Universidades para o número de alunos que existem. Ou então as Universidades têm de financiar-se, em grande percentagem, pelo exterior. 0 que também em Portugal é muito difícil porque não há mercado.

Tem uma obra publicada muito vasta, não só no domínio da investigação fundamental, mas no ensino na divul- gação e na reflexão sobre a ciência. Qual é a importância que atribui ao reflectir sobre a ciência e sobre a forma como se desenvolve a actividade científica. $\mathrm{O}$ cientista será a pessoa melhor colocada para fazer essa reflexão?

Pelo menos é uma das pessoas que deve reflectir. Claro que embarquei nesse aspecto, exactamente para lidar com a resistência da comunidade às teorias que tinha proposto, particularmente com o modelo de intersecção de estados; até lá esse interesse existia, mas não era tão profundo que me levasse a ter uma reflexão atenta sobre esse problema. Não direi que todos os cientistas têm de reflectir, mas pelo menos deveriamos dar aos jovens, aos estudantes, a imagem que a Ciência não é aquela instituição neutra, asséptica, objectiva per se; a objectividade tem de se conquistar, há dificuldades, há resistências. É evicente que a história depois só regista os triunfos; mas talvez alguns casos que não são triunfos, e os seus contextos, também fossem úteis de serem examinados. Mas há necessidade de ser feita por um cientista, porque ele é que conhece profundamente a ciência. Os historiadores da ciência que não sầo cientistas têm mais dificuldades em lidar com os conceitos. Claro que dão-nos uma outra história, interessante. Talvez os cientistas criem histórias muito mais coloridas, de triunfos e derrotas. Mas talvez as duas leituras sejam úteis e devam permanecer no contexto do que é a imagem da ciência. Claro, aquela que tem vitórias e derrotas profundas é a que interessa mais o público. Isso é um aspecto que pode interessar, ser um modo de cativar jovens para a ciência.

Como católico, cientista e autor de textos sobre o tema ciência e religião, qual a sua opinião sobre os limites da actividade científica? Pode um cientista investigar em tudo aquilo que tiver vontade? Ou devemos impor limites, morais, éticos ou de qualquer outra índole?

Eu julgo que sim, que tem de haver limites. Agora na manipulação genética esses problemas contam, mas não se confrontam tanto para um Químico. Do ponto de vista genético esses problemas são muito marcantes. Por exemplo a clonagem de seres humanos é algo que nos choca, não só por levar ao aparecimento de um ser humano, mas basicamente se a sociedade fosse toda feita de clones, não nos poderíamos reconhecer, era tudo igual. Mesmo para um Químico há responsabilidades sociais para as quais nós hoje estamos atentos, após a bomba atómica, e por isso mesmo na questão da co-incineração nós, como cientistas, temos responsabilidades; temos de alertar para o facto de termos resíduos tóxicos por aí "armazenados", a intoxicar as pessoas; nós (comissão independente) vamos acabar, mas a responsabilidade individual não, nós temos que alertar a população nesse sentido. $\mathrm{O}$ que eu noto, é que todas aquelas pessoas, as faculdades, os médicos particularmente, que alarmaram as populações sobre os perigos das dioxinas, quase diziam que nasciam os fetos sem cabeça, etc., agora que o problema surge sem solução, estão calados que nem ratos. Ė uma profunda contradição. Se aquilo era perigoso, evidentemente os perigos estavam empolados, deveriam continuar a pugnar sob um ponto de vista de saúde pública, pela resolução do problema. Mais uma vez 0 aspecto da contradição, que eu também já notava na altura; isto revela sempre que há outra razão qualquer, que não foi explicitada.

\section{Que não é a ciência...}

\section{Que não é a ciência.}

Sendo membro da Academia das Ciências, autor de centena e meia de artigos científicos, de livros, tendo obtido diversos prémios, entre os quais o prémio Gulbenkian de Ciência, e a medalha Ferreira da Silva da Sociedade Portuguesa de Química, sente-se satisfeito com o seu percurso?

O percurso, julgo que sim, quer dizer...não sei se poderia ter feito mais, mas se me deu prazer? Com certeza que sim. É óbvio que desloquei-me um pouco mais das tarefas científicas, que nâo larguei, para outros assuntos, de escrita, de divulgação, etc., porque também tinha de passar o tempo. Essas coisas sāo muito morosas na resistência, 
muito complicadas, e a pessoa não se pode dedicar inteiramente a elas porque, como a história já mostrou, é todo um modo de vida que fica truncado pela comunidade e que cria efeitos psicológicos importantes; e portanto esperamos até do mal extrair algum bem.

"Tiro algum prazer da escrita, digamos...escreve para quê"? Essencialmente é para mim próprio, porque me dá prazer, e depois julgo que pode ser útil para outros. Mas isso é também um modo de limpeza da mente.

\section{Gostaríamos de terminar esta entre-} vista perguntando-lhe, quais os seus projectos para o futuro?

No que diz respeito à ciência é óbvio que continuamos a lutar pelo modelo de intersecção de estados. Passá-lo à forma de livro, de programas, torná-lo socialmente aceitável pelas comunida- des. No que diz respeito à Universidade, ver o que é que dá esta evolução do modelo universitário em Portugal, com um meio social limitado, com a ausência de grandes grupos, como é que a universidade pode realmente valorizar o seu produto intelectual.

\section{Referências}

1 Journal of the Royal Chemical Society, Faraday Transactions

20 artigo em questão foi também publicado no nosso boletim, Química, $n^{\circ} 85, \mathrm{p} 12$

3 Modelo teórico, alternativo/complementar ao de Marcus, usado para estudar as reacções de transferência de electrão e de protắo, "A Critical Assessment of Classical and Semi-classical Models for Electron Transfer Reactions in Solution.", S. J. Formosinho, L.G. Arnaut, R. Fausto, Prog. React. Kine- tics, 23 (1998) 1-90; "The Intersecting-State Model: a Link between Molecular Spectroscopy and Chemical Reactivity.", L. G. Arnaut, A. A. C. C. Pais, S. J. Formosinho, J. Mol. Struct., 563/564 (2001) 1-17.

4 "O valor da Heterodoxia e a necessidade da sua comunicaçăo", Revista de Ciência, Tecnologia e Sociedade 19/20, 24-30 (1993); "A visibilidade da Heterodoxia científica", Bol. Soc. Port. Quím. 52 (1994) 13-14

5 Prof. Rodolph Marcus, prémio Nobel da Quimica em 1992.

6 Manuel Dossot e Patrice Jacques, "Intrinsic rate constants ket of photoinduced electron transfer between anthracene derivatives and aromatic donors: does the intersectingstate model challenge Marcus Theory when confronted with an archetypal set of data", Helv. Chim. Acta, 84 (2001) 3446.

7 Michael Athans, "Portuguese research universities: why not the best", texto que circulou por email, em formato pdf, e que foi tema de uma conferência proferida em Junho 2001.

\section{Perfil biográfico do Professor Sebastião José Formosinho}

Sebastião José Formosinho Sanches Simōes nasceu em Oeiras a 19 de Setembro de 1943, completando a Licenciatura em Ciências Físico-Químicas na Universidade de Coimbra em 1964, e doutorando-se em Química na Universidade de Londres em 1971.

Iniciou a sua actividade de investigação no antigo Laboratório Químico da Universidade de Coimbra sob a orientação do Professor Fernando Pinto Coelho em estudos de condutividade de soluções. Nessa altura, esteve também envolvido em estudos espectroscópicos utilizando ressonância paramagnética electrónica com o Professor Jorge dos Santos Veiga e ressonância magnética nuclear com o Professor Victor M.S. Gil. Em 1966 foi bolseiro no Laboratório de Química da Universidade de Moçambique onde trabalhou com o Professor José Simões Redinha em condutividade de sais inorgânicos em solventes mistos.
Entre 1968 e 1971 trabalhou no Davy Faraday Laboratory da Royal Institution, Londres, sob a orientação de Lord George Porter no estudo de processos fotofísicos de moléculas aromáticas em fase gasosa. Voltando a Coimbra, continuou a investigação em fotoquímica, montando um laboratório dedicado. Ao mesmo tempo começou estudos teóricos de reacções fotoquímicas e de desactivação fotofísica, desenvolvendo um modelo de efeito túnel para esses processos. Posteriormente o modelo foi utilizado para tratar processos no estado fundamental. Desde aquela época as investigações do Professor Formosinho alargaram-se a um grande espectro da química-física, que correntemente incluí, entre outros, o modelo de intersecção de estados e suas aplicaçōes em processos químicos e biológicos, estudos de transferência de energia e de electrões e terapia fotodinâmica. Além desses estudos em química-física, os seus interesses englobam aspectos da filosofia, teologia e história de ciências. Publicou 20 livros, cerca de uma centena e meia de artigos científicos em química-físi$\mathrm{ca}$, além de 30 artigos em outras áreas. Com um currículo tão vasto é natural que tenha recebido vários prémios científicos, onde se incluem o Prémio Artur Malheiros da Academia de Ciências de Lisboa, a MedaIna Ferreira da Silva da SPQ e o Prémio Gulbenkian de Ciência.

A sua carreira docente começou em 1964 com a sua contractação como $2^{\circ}$ Assistente. Rapidamente ascendeu as escadas da carreira académica e foi aprovado para um lugar de Professor Catedrático na Universidade de Coimbra em 1979, onde presentemente é o Professor Decano. Leccionou nas várias áreas de química, desde Química Geral até Química e Sociedade.

Foi Presidente do Conselho Científico da Faculdade de Ciências e Tecnologia da Universidade de Coimbra entre 1978 e 1979 . Foi Secretário do Estado do Ensino Superior no $6^{\circ}$ e $7^{\circ}$ Governo. Entre 1992 e 1998 foi Presidente da Sociedade Portuguesa de Química, onde presentemente é Pre- 
sidente da Assembleia Geral. Foi nomeado Presidente da Comissão Científica Independente no estudo do processo de Co-imcineração. Desde 1994 é Vice-Reitor do Centro Regional das Beiras da Universidade Católica Portuguesa.

Também é membro da Comissão Editorial do Journal of Photochemistry and Photobiology A: Chemistry. Foi membro das comissões organizadoras de muitos congressos internacionais e nacionais. Uma nota especial deve ser feita sobre o "Seminário sobre Estados Excitados", organizado em Coimbra em 28 de Maio de 1974 , o primeiro da série de encontros Portugueses de Fotoquímica, que ainda perduram.

Destaco duas histórias a nível pessoal. Entre 18 e 24 de Abril de 1974 realizou-se em Lisboa o congresso internacional sobre "Excited States in Biological Molecules", organizado por Bob Cundall, Mike Lumb, John
Birks, Sebastião Formosinho e outros. Eu e o Professor Formosinho saímos de Lisboa num dos últimos comboios no dia 24. Tinhamos marcado para o dia seguinte a montagem do primeiro aparelho de fotólise por relâmpago com resolução temporal de nanosegundos no país, no Instituto Geofísico da Universidade de Coimbra. Assim no dia seguinte fui ao Instituto Geofísico, sem ligar o rádio, encontrando o técnico inglês da Applied Photophysics, Doutores Formosinho, Abílio Marques da Silva e outros em grande discussão, e nessa altura descobri os grandes acontecimentos do 25 de Abril! Devo dizer que o aparelho não foi montado nesse dia!

Outra história é uma lição para a comunidade médica portuguesa. Devido a um acontecimento num avião em Moçambique e durante muitos anos, o Professor Formosinho não viajou em aviōes. Este facto limitou a sua participação em Congressos, etc para os países em que não se pode chegar por carro, comboio ou barco. Aconteceu que foi convidado para um Congresso importante de Fotoquímica em Itália e, considerando que a viagem levava 3 dias, o Professor Formosinho decidiu que deveria ultrapassar o medo dos aviões. Foi ao médico, tendo este referido ser este um medo muito comum, podendo aconselhar uma receita envolvendo alguns calmantes, mas que seria muito melhor utilizar uma forma de tratamento tradicional, consistindo em: meia hora antes do vôo tomar um whisky; cinco minutos antes do vôo tomar outro whisky. O Professor Formosinho aceitou este tratamento e desde esta data já voou até quase todos os continentes!

Hugh D. Burrows

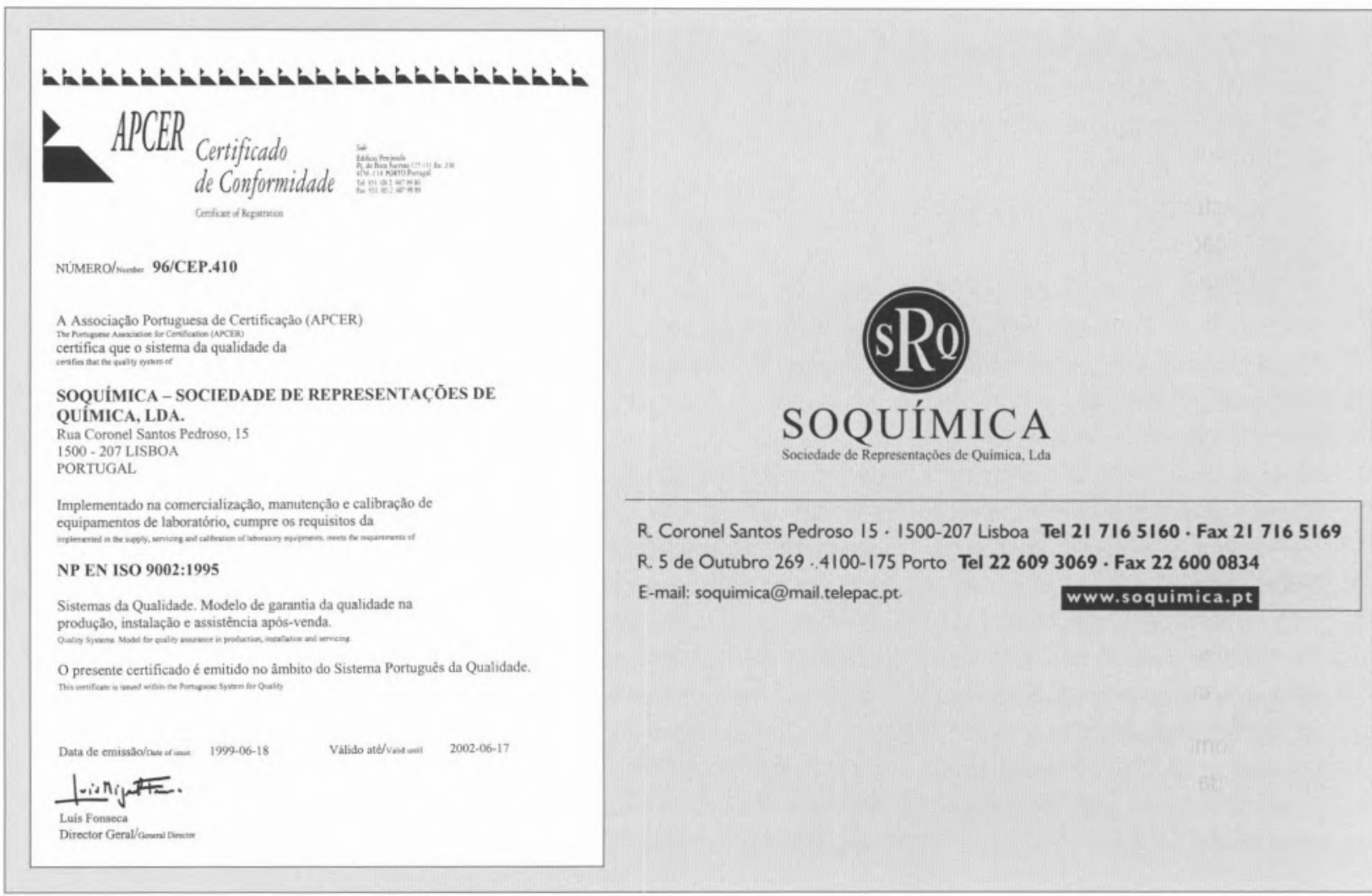

